\title{
PORNOGRAFIA ALÉM DA MÍDIA
}

\section{PORNOGRAFÍA MÁS ALLÁ DE LA MEDIOS DE COMUNICACIÓN}

PORNOGRAPHY BEYOND THE MEDIA

\author{
Luiz A. Calmon Nabuco LASTÓRIA ${ }^{1}$
}

RESUMO: O presente artigo tem por objetivo refletir sobre o tema da pornografia na atual sociedade de consumo. Para tanto partiremos do vínculo entre a literatura pornográfica e a Revolução Francesa e prosseguiremos mostrando como as sociedades liberais de consumo representam uma particular síntese de liberdade e gozo.

PALAVRAS-CHAVE: Pornografia. Consumo. Gozo.

RESUMEN: El presente artículo tiene por objetivo reflexionar sobre el tema de la pornografía en la actual sociedad de consumo. Para ello partiremos del vínculo entre la literatura pornográfica y la Revolución Francesa y proseguemos mostrando cómo las sociedades liberales de consumo representan una particular síntesis de la libertad y el goce.

PALABRAS CLAVE: Pornografía. Consumo. Goce.

ABSTRACT: The aim of this article is to reflect on pornography in consumer society nowadays. The link between pornographic literature and the French Revolution will be our starting point. We will continue then to show how liberal consumer societies represent a particular synthesis of freedom and pleasure.

KEYWORDS: Pornography. Consumption. Pleasure.

\section{Introdução}

O presente artigo tem por objetivo refletir sobre o tema da pornografia na atual sociedade de consumo. O termo "pornografia", derivado do grego porné, designa os escritos sobre o comércio sexual no âmbito da prostituição. Para os nossos propósitos o termo será empregado em sentido metafórico com o intuito de descrever o modus operandi próprio a este tipo de sociedade. Hunt (1999) chamou atenção para o fato de

${ }^{1}$ Prof. Dr. do Departamento de Psicologia da Educação - Faculdade de Ciências e Letras - UNESP, Araraquara-SP. E-mail: lacalmon@fclar.unesp.br 
que a pornografia constitui um fenômeno próprio às sociedades ocidentais modernas; e cuja gênese deveu-se a um longo e conflituoso processo desencadeado a partir do renascimento italiano. Artistas, sobretudo escritores, pintores e gravadores, de um lado, e, espiões, padres, policiais e funcionários do estado, de outro, constituíram os polos desse conflito. Assim, a pornografia enquanto gênero próprio teria se definido por meio dos esforços sociais empreendidos para o controle de determinadas obras, e práticas, vinculadas ao âmbito da sexualidade consideradas licenciosas à época.

Kendrik (HUNT, 1999) situou sua gênese no período compreendido entre o final do século XVIII e as primeiras décadas do século XIX. No referido período, a delimitação de espaços socialmente restritos, e estritamente regulamentados para as práticas de consumo do obsceno ${ }^{2}$; bem como o crescimento do número de publicações sobre o tema da prostituição atestam o surgimento de novas práticas sociais de controle por meio das quais o gênero pornográfico teria, pouco a pouco, se constituído. Isso já num cenário social pré-burguês fortemente marcado pela difusão literária, e, pouco mais tarde, educacional. Pode-se dizer, então, que enquanto categoria representativa visual ou literária: "A pornografia começou a aparecer como gênero distinto de representação quando a cultura impressa possibilitou às massas a obtenção de escritos e ilustrações" (HUNT, 1999, p. 13).

Importante salientar que a "pornografia" durante o século XVIII, assumiu, primeiramente, a forma de panfleto político destinado a veicular um conjunto de ideias imprescindíveis ao sucesso da Revolução Francesa (1789 - 1799). A esse respeito comentou Hunt: "Entre 1740 e 1790, a literatura pornográfica francesa tornava-se cada vez mais política. Nas críticas mais agudas à monarquia, os panfletos pornográficos atacaram o clero, a corte e, no caso de Luís XV, o próprio rei” (HUNT, 1999, p. 36). Na década pós-revolucionária, acrescenta a autora: "um novo dilúvio de panfletos pornográficos políticos e de uma literatura que retomou a tradição pornográfica, culminando nos escritos de Sade" (HUNT, 1999, p. 36), eclodira selando o compromisso da então chamada "literatura libertina" com o evento político de maior envergadura para o período moderno subsequente. E, ainda: que durante a década de 1790, as descrições cruas das relações sexuais permaneceram subversivas. No entanto, entre o período de 1790 a 1830, a pornografia perdera paulatinamente a sua conotação

2 A Collection de l' Enfer (1836) situada no interior da Biblitheque Nacional de Paris permaneceu até 1922 como um desses lugares. A esse respeito ver o texto de Robert Darnton "Sexo dá o que pensar” IN: NOVAES, A. (org.) Libertários libertinos. São Paulo: Companhia das Letras, 1996. 
política até se reduzir a um nicho comercial de mercado tal como hoje nós a encontramos.

O intenso veto político que essa forma de expressão de conteúdos sexuais chegou a representar ao final do século XVIII entre as massas terminou por ceder ao veto puramente moral da sociedade burguesa em ascensão. Destarte, a pornografia viria assumir a forma metafórica apropriada para designar a lógica determinante do consumo em geral nesse tipo de sociedade. Vejamos como isso se tornou possível.

As duas grandes fontes do Iluminismo brotam do critcismo tanscendental de Immanuel Kant e do liberalismo do continuador das ideias de Mandeville, Adam Smith. O ponto nodal de divergência entre ambas reside no modo de regulação moral por elas indicado. Tanto a Metafísica dos Costumes (Kant) como a Teoria dos Sentimentos Morais (Smith) nos oferecem pontos de vista acerca dos modos de regulação moral dos indivíduos na sociedade. Porém, estes modos são diametralmente opostos: imperativo categórico versus desregulamentação. Para Dufour (2013) a modernidade consistiria num período histórico fundado no equilíbrio instável entre essas duas fontes; já a chamada "pós-modernidade" consistiria na prevalência da segunda sobre a primeira. Uma época em que a noção kantiana de "dignidade" sucumbiria à noção smithiana de 'preço'.

Ainda conforme Dufour, entre o iluminismo levado a cabo na Alemanha e na Inglaterra, a França, embora tenha oscilado entre as duas correntes, sobretudo com Rousseau e Helvétius, se distinguiu na cena filosófica do século XVIII por meio das contribuições de um outro continuador das ideias de Mandeville: o Marques de Sade. Sade desnudou a lógica imperante nas sociedades liberais, levado-a, literariamente, as últimas consequências.

Com base tanto na oposição quanto no conteúdo normativo propriamente dito, tal como este fora explicitado pelas duas fontes do iluminismo supracitadas, o autor encaminhará a sua análise no sentido de distinguir, radicalmente ${ }^{3}$, uma moral altruísta de uma moral egoísta; e, portanto, a lei moral kantiana da lei do gozo sadiana. Esta última vista como a representante fiel da lógica imperante nas sociedades liberais de consumo contemporâneas. Logo, se visto como a resultante dessas duas fontes, o liberalismo teria, tal como Janus, duas faces: uma puritana e outra perversa. Traduzido

3 Não nos interessa nos limites deste artigo explorar o denominador comum entre ambas; operação que requer considerar certa homologia estrutural quanto à relação do sujeito à lei (seja ela concebida como lei moral ou do coração), de um ponto de vista crítico. 
em termos econômicos poderíamos dizer: uma síntese de liberalização do mercado (Adam Smith como representante da versão puritana do liberalismo) com o incentico ao gozo a qualquer preço (Sade na melhor versão da literatura pornográfica). Em total consonância com a perspectiva esclarecida por T. W. Adorno e M. Horkheimer, Dufour matiza a ideia segundo a qual Sade é quem melhor representaria a verdade do liberalismo. E, por esse motivo, Sade teria sido já em sua época, duramente castigado, enquanto o pensamento liberal tomado em sua vertente puritana (Smith) ganharia terreno se espalhando pelo mundo.

Mas, tal como ocorre com a questão do retorno do recalcado, na visada psicanalítica, também o retorno do escritor e dramaturgo Sade à cena moderna se afigurou sintomática. Fato que teve lugar numa ambiência social e numa época propícia: em meio à cultura protestante dos EUA durante a crise de 1929. Nesse período as fórmulas liberais clássicas haviam se mostrado inoperantes. Noutras palavras: a mão invisível de um mercado, supostamente capaz de se autorregular, havia estancado. E, naquela conjuntura, o receituário econômico liberal passou a ensejar os trustes, e as camarilhas econômicas das quais nomes como J. Rockefeller (óleo) e W. Vanderblit (ferrovias) integraram à época. A partir de então a lógica concentracionista do capital deu passagem ao holigopolismo e à financeirização, gerando crises cíclicas de maiores proporções, como é o caso da que experimentamos atualmente em nível global.

Mas o que retornou à cena, de fato, foi o espírito libertino-pornográfico do teatro sadiano como fonte de inspiração de um desfile de modas, realizado em 31 de março de 1929 na Quinta Avenida, em Nova Iorque, aos arredores do Central Park. Nesse desfile um conjunto de belas mulheres excitadas exibiram um comportamento felatório levando a boca desejosa um objeto comprido com a ponta arredondada (exatamente o falo que o perverso, por negar a diferença anatômica entre os sexos, julga faltar na mulher). $\mathrm{O}$ objeto em questão que essas mulheres levavam à boca portava um nome preciso: "tocha da liberdade". Uma referência explícita ao sexo (direito ao gozo, ou mais precisamente, a um certo tipo de gozo, por parte das mulheres; agora elas mesmas possuidoras de um pênis); e, concomitantemente uma referência explícita ao liberalismo em termos político-econômicos. Do ponto de vista estritamente econômico, as mulheres representavam à época um significativo contingente populacional para os fabricantes de cigarros. Restava então profanar o puritanismo protestante norte-americano e induzi-las 
a fumar publicamente. Tarefa essa levada a cabo por ninguém menos que Edward Bernays $^{4}$ - sobrinho de Freud -, e, especialista em manipulações publicitárias.

Logo após o desfile constatou-se o enorme sucesso proporcionado pela associação ilusória (porque fetichista) entre o comportamento de fumar e a emancipação feminina. Se o preço dessa suposta emancipação é o vício numa droga considerada leve, isso constituiria apenas um detalhe frente ao ganho obtido. Dufour (2009) ressalta que: "Todo o espírito do novo capitalismo do consumo pode ser lido nesse ato inaugural de Bernays" (p. 157). Liberação mercadológica associada a uma demanda de gozo engendrada em meio ao puritanismo: eis aí a fórmula do sucesso que alavancaria a indústria em direção à sociedade democrática de consumo associada ao crédito. Sade então retorna à cena social como o inspirador de uma política em prol da liberação de todas as paixões humanas no mesmo diapasão do panfleto situado entre o quinto e o sexto capítulos de sua Filosofia da Alcova: "Franceses, mais um esforço se quereis ser republicanos".

Ainda conforme as palavras de Dufour (2009), de lá para cá (...) "somos sadianos mais ou menos 'gazeados' em função do momento, já que cada um de nós é considerado, antes de mais nada, como um consumidor potencial, vale dizer, um candidato à liberação de uma paixão ou a satisfação de uma pulsão" (DUFOUR, 2009, p. 160). Liberalismo econômico mais democracia política resultaria então numa dinâmica sistêmica em que o gozo confiscado na produção retorna ao trabalhador mediante democratização dos gozos via consumo. Quando da passagem ao novo espírito do capitalismo uma cultura de excessos, thanática, por excelência, se instaurou em nível planetário.

Uma vez localizado o evento emblemático de uma política cripto-sadeana posta em marcha em meio à crise de 1929, Dufour avança suas análises mobilizando inúmeros eventos culturais e fatos políticos com o intuito de mostrar como uma cidade perversa ganha corpo por intermédio de tal política. Das pin-ups criadas pelos desenhistas George Petty e Alberto Vargas até Carla Bruni - modelo e mulher do ex-presidente francês N. Sarcozi -, passando pelas pompom girls, coelhinhas da Play Boy, bonecas sexuais infláveis, estrelas pornô comandando programas televisivos de entretenimento para as massas, dentre outros, o mercado e os respectivos atores sociais dão mostras de que uma cultura pornográfica ad libitum se instalou como ponto de confluência entre a

\footnotetext{
${ }^{4}$ A esse respeito ver Zaretsky, E. (2004) Segredos da Alma: Uma história sociocultural da psicanálise, especialmente o capítulo VI: "Fordismo, freudismo e modernidade".
} 
economia libidinal e a economia mercante, de modo a conformar uma vertente soft e outra hard.

Assim, sob a capa de uma perversão supostamente "puritana", Sade teria socorrido Adam Smith numa espécie de manejo paradigmático de uma das crises cíclicas do capitalismo ainda em sua fase de livre concorrência. Tese que apenas confirma a concepção segundo a qual o modo de produção capitalista seria pornográfico desde sempre. Isto na medida em que se baseia na sociedade de mercado universal. Pois, estar no mercado significa, ao menos desde Marx, vender-se enquanto força de trabalho. A parte do corpo que cada um dispõe à venda para sobreviver torna-se indiferente perante o mercado universal. $\mathrm{E}$, dado que o capitalismo se baseia na lei da acumulação do valor e também no equivalente geral de troca, o modo de produção capitalista só pode se realizar de forma promíscua (trocando tudo por tudo por intermédio do equivalente geral do valor); e orgiástica (obedecendo aos ciclos de valorização crescente do valor).

As vertentes hard e soft da pornografia em operação no mercado capitalista se materializam através do que o autor denomina "pequenas narrativas"; narrativas essas que povoam o tecido social de modo a preencher o vácuo deixado pelas grandes narrativas (Lyotard). Trata-se aqui, a bem da verdade, das sofisticadas retóricas publicitárias cujo modelo das análises mais penetrantes nós devemos a Horkheimer e Adorno desde os anos 40, época do exílio norte-americano. No âmbito do chamado “marxismo ocidental”, Dufour opta por encaminhar as suas análises pela via aberta por A. Gramsci ao sustentar que a sobrevivência do capitalismo, esse modo de produção que revoluciona a si mesmo ininterruptamente, se deve às assim chamadas "revoluções passivas", isto é, políticas de "redistribuição do gozo". Tais "revoluções" implicariam na produção de mecanismos capazes de promover reconfigurações de modos substanciais de manutenção da hegemonia burguesa sob o capitalismo.

Ocorre que a vertente pornográfica soft ("sadismo ordinário") do mercado desliza tendencial e constantemente para a vertente hard ("sadismo extraordinário"). O capitalismo atual comenta Dufour (2009), "reivindica cada vez mais abertamente seu funcionamento de tipo sadeano. O momento é de cinismo descomplexado, de ostentação do egoísmo como valor supremo e de difusão maciça das lições da perversão" (DUFOUR, 2009, p. 207). Predomínio de comportamentos autodestrutivos e aumento da violência crua, destituída de mediações, passam ao primeiro plano. Nesse cenário social verifica-se igualmente a passagem das buscas no plano erótico sem limites de 
modo a conformar uma estética pornográfica do grotesco. Isto na medida em que a busca incessante pelo objeto mesmo, que, conforme nos ensina a psicanálise, para os seres humanos redunda na busca pelo objeto perdido (ou objeto causa do desejo), faz com que os closes terminem por exibir as tripas durante os atos sexuais. Em suma: deparamo-nos atualmente com uma estética que privilegia a passagem ilimitada das representações, esse artifício tão caro às sociedades burguesas, às exibições extremadas e destituídas de quaisquer puderes.

A esse respeito nos limitaremos a sublinhar que também para Adorno e Horkheimer (1984), a personagem sadeana Juliette constitui a representação do sujeito esclarecido moderno; aquele que maneja impecavelmente a lógica e que se mostra liberto da tutela de outrem. Enfim, Juliette representa o indivíduo burguês emancipado nos próprios termos da versão germânica do iluminismo (Kant). Ocorre que, críticos das patologias da própria razão, esses frankfurtianos verão em Sade, e também em Nietzsche, o giro radical da crítica à razão iluminista, giro esse apenas iniciado com o criticismo kantiano - na Crítica da Razão Prática. Somente nesse diapasão o título do segundo excurso "Juliette ou esclarecimento e moral", da obra Dialética do Esclarecimento, adquire sentido.

Passemos agora à ilustração da pornografia "além da mídia"; ou dito de outro modo: como indicador do modus operandi próprio à sociedade de consumo atual.

\section{Considerações sobre as pequenas narrativas publicitárias: sexo, moda e mercado}

Num belo ensaio intitulado Elogio da Profanação, G. Agamben menciona os juristas romanos como aqueles que conheciam muito bem o significado do ato de profanar. Se consagrar (sacrare) significava a retirada das coisas da esfera do direito humano - disposição de uso, comércio, doação ou fiança, profanar significava, por sua vez, restituí-las ao livre uso dos homens. À religião cabia, exatamente, subtrair coisas, lugares e animais para uma esfera separada - porque divina - por meio de práticas sacrificiais ritualizadas. Algo que fora separado mediante os ritos poderia ser profanado pelo simples contato humano (contagione). Tocar em certas partes de um animal abatido como oferenda aos deuses fazia das partes tocadas, terrenas novamente, e, portanto, liberadas para serem consumidas. 
Assim, a verdadeira atitude de oposição à religião, esclarece o autor, não seria a incredulidade ou mesmo a indiferença, mas antes a negligência quanto às normas que tornam as coisas separadas quanto aos seus significados e usos particulares. A esse respeito nos argumenta Agamben: "Profanar significa abrir a possibilidade de uma forma especial de negligência, que ignora a separação, ou melhor, faz dela um uso particular" (AGAMBEN, 2005, p. 66). Agamben, portanto, enxerga nessa possibilidade de liberação capaz de ensejar outros "usos particulares" o potencial de emancipação a ser evocado pelas práxis política contemporânea. Isso uma vez que o ato profanador neutraliza - ou melhor, desativa - aquilo que profana:

Depois de ter sido profanado, o que estava indisponível e separado perde a sua aura e acaba restituído ao uso. Ambas as operações são políticas, mas a primeira tem a ver com o exercício do poder, o que é assegurado remetendo-o a um modelo sagrado; a segunda desativa os dispositivos do poder e devolve ao uso comum os espaços que ele havia confiscado (AGAMBEN, 2005, p. 68).

Aganbem chama atenção para uma ambiguidade em termos filológicos: profanar significa tornar profano; mas em alguns poucos casos, também, sacrificar. Tal ambiguidade constitutiva das operações consagratórias/profanatórias se expressa igualmente no adjetivo sacer que significa a um só tempo sagrado e maldito. "Enquanto se referem a um mesmo objeto", argumenta o autor, "que deve passar do profano ao sagrado e do sagrado ao profano, tais operações devem prestar contas, cada vez, a algo parecido com um resíduo de profanidade em toda coisa consagrada e uma sobra de sacralidade presente em todo objeto profanado" (AGAMBEN, 2005, p. 68). O homo sacer encarnaria exemplarmente essa contradição: aquele que expulso ritualisticamente de sua comunidade, e que sobrevive ao ritual dando prosseguimento a sua existência profana, pode ser morto impunimente, mas não pode mais ser ofertado aos deuses uma vez que a eles já pertence. O resíduo sacro inere a sua carne, e, ao mesmo tempo, o expõe à morte violenta na medida em que introduz um resto incongruente de profanidade no âmbito sagrado. Se as práticas sacrificiais ensejam tal ambiguidade quando da separação entre o sagrado e o profano, elas não o fazem isenta de certa promiscuidade.

$\mathrm{O}$ autor alude ao fato de que $\mathrm{W}$. Benjamin notara com profunda agudeza o caráter essencialmente religioso do capitalismo para além da mera secularização da fé 
protestante, tal como antevista por Max Weber. Tratar-se-ia da religião da modernidade por excelência. Extremamente cultual, pois na sociedade de consumo o culto se torna permanente de modo a apagar a diferença entre os dias de festa e os dias de trabalho; nela o culto se volta para a má consciência e não para a expiação ou para a redenção. Uma monstruosa consciência infeliz se estende, com o capitalismo, ao infinito, e, a partir dela, Deus se torna cúmplice do destino dos homens. Nesses termos, o capitalismo não tende à redenção dos homens, mas à destruição do planeta.

Ouçamos Agamben a esse respeito:

Na sua forma extrema, a religião capitalista realiza a pura forma da separação, sem mais nada a separar. Uma profanação absoluta e sem resíduos coincide agora com a consagração igualmente vazia e integral. E como, na mercadoria, a separação faz parte da própria forma do objeto, que se distingue em valor de uso e valor de troca e se transforma em fetiche inapreensível, assim agora tudo o que é feito, produzido e vivido - também o corpo, também a sexualidade, também a linguagem - acaba sendo dividido por si mesmo e deslocado para uma esfera separada que já não define nenhuma divisão substancial e na qual todo uso se torna duravelmente impossível. Esta esfera é o consumo (AGAMBEN, 2005, p. 71).

Consumo e exibição espetacular; pornografia e moda. Duas indústrias regidas pelo mesmo denominador comum: o capital. No entanto, Aganbem argumentará também a partir da bula Ad conditorem canonum, escrita por João XXII que o consumo, cuja existência se define apenas no ato de consumir (abusus), não se presta ao uso (no sentido da propriedade - dominium) na medida em que destrói o objeto consumido. Pois, o próprio ato de consumo se define temporalmente apenas no instante do seu desaparecimento de modo que a sua existência real pertence à memória ou à expectativa. Logo, o consumo revelaria a natureza mesma do valor de uso da propriedade como aquilo (dispositivo) que desloca o livre uso dos homens para a esfera do direito. Daí a infelicidade reinante nas atuais sociedades de consumo em que as massas não se apropriam de nada que consomem acreditando que exercem o direito de propriedade sobre os objetos consumidos. Permanecer atado aos ciclos do consumo de mercadorias resulta em permanecer atado ao mal-infinito atávico do excesso destituído de sentido próprio. Se o museu representa o espaço reservado aos objetos subtraídos ao uso, lembra o autor, então a museificação do mundo (e também das pessoas) atesta a nossa incapacidade política atual de profanar em meio à sociedade de mercado. 
Perspectiva que aponta para o museu, como uma espécie de "templo moderno", enquanto lócus privilegiado em que se verifica a analogia benjaminiana entre o capitalismo e a religião. Se o templo denotava o lugar de sacrifício, hoje, as massas de turistas peregrinam de museu em museu num mundo cada vez menos próprio, inabitável, e cada vez mais carente de sentido; somente que perderam a possibilidade própria à religião: promover a separação entre o sagrado e o profano. No mundo hodierno "os turistas celebram, sobre a sua própria pessoa, um ato sacrificial que consiste na angustiante experiência da destruição de todo uso possível" (AGAMBEN, 2005, p. 73). Assim a massa de adeptos do novo culto capitalista permanece despatriada na Terra, agora resplandecida sob a luz do esclarecimento científico, e também privada da esperança celestial.

A linguagem - comportamento verbal que fora "separado" ao longo do desenvolvimento filogenético alcançando certa estabilidade e autonomia em relação aos fins - se deixa capturar pelo poder devido à necessidade de controle racional tecnológico da comunicação social. Essa função instrumental da linguagem sofreu uma mutação na contemporaneidade: "Os dispositivos midiáticos têm como objetivo, precisamente, neutralizar esse poder profanatório da linguagem como meio puro, impedir que o mesmo abra a possibilidade de um novo uso, de uma nova experiência da palavra" (AGAMBEN, 2005, p. 73). E essa aniquilação, constata Aganbem, pode ser verificada no dispositivo maior que parece ter realizado o sonho capitalista da produção: a pornografia.

Com a absolutização capitalista do valor de troca, o erotismo romântico dá passagem a uma exibição performática da uma sexualidade absolutamente impúdica que flerta com o expectador. Benjamin já havia comentado em 1936, a propósito do ensaio de Fuchs: "o que nestas imagens atua como estímulo sexual não é tanto a visão da nudez quanto a ideia da exibição do corpo nu frente à objetiva" (BENJAMIN apud AGANBEM, p. 77). Portanto, o valor de exposição, valor subtraído ao uso e que não diz respeito à mensuração da força de trabalho, passa ao primeiro plano na sociedade que os situacionistas franceses batizaram de "sociedade do espetáculo". Por seu turno, Aganbem vê no rosto da mulher cujo semblante se torna imparcial quando percebe que está sendo admirada, a sede maior do valor de exposição. É por meio da aniquilação de toda expressividade que o erotismo (e não o pornográfico) penetra o rosto como aquela parte do corpo humano desnuda desde sempre. Exibi-lo de modo imparcial caracterizaria, então, a façanha artística do trabalho fotográfico de Chlöe des Lysses. 
Isto de modo a subverter a pornografia desativando-a e liberando-a para uma nova forma de comunicação erótica.

Mas se Aganbem viu no trabalho fotográfico da pornô-star francesa um exemplo de profanação, V. Safatle (2008), por sua vez, chamou atenção para o fato de que Agamben teria chegado apenas a nos indicar modos de profanação, de real conteúdo disruptivo, muito frequentes nas atuais retóricas publicitárias: "ao defender distinções entre uso profanador e consumo pensado como submissão dos objetos ao gozo advindo do direito de propriedade, objetos submetidos à lógica utilitária do serviço dos bens" (SAFATLE, 2008, p. 176). No entanto, admite que os exemplos escolhidos por Agamben não seriam os melhores para ilustrar uma tal partilha.

Dentre esses exemplos destaca-se o trabalho de Chloë des Lysses, cuja façanha consiste em deixar-se fotografar em tórridas cenas de conteúdo sexual com o rosto impassível de uma manequim:

Agamben vê nessa gramática o rosto mesmo da inexpressividade e da indiferença estóica lá onde deveríamos encontrar a representação codificada do gozo. Essa seria uma forma de desativar o dispositivo fascinante da pornografia através de uma ação que mimetiza as formas próprias à linguagem pornográfica, mas de uma maneira tal que certo 'distanciamento irônico', certa autoderrisão é encenada, provocando com isso o estranhamento lá onde esperávamos apenas a repetição fantasmática. Ao encenar fantasmas 'clássicos' de filmes pornográficos, como a secretária, a executiva, a empregada, a garota mignon currada por um negro, a garota rica e devassa, ela age como se estivesse totalmente presa aos códigos da pornografia barata. Mas, ao fazer que seus olhares, suas feições, suas roupas fashion nos remetam a um outro código, o das revistas internacionais de moda, com seu 'glamour' feminino desafetado, Chlöe des Lysses produz uma duplicidade de códigos que nos lembra que ela não está totalmente absorta no que faz. Daí a noção de profanação como agir paródico, agir daqueles que fazem o que, no fundo, procuram destruir. Agir que desativa a potência ordenadora e identitária do código no momento mesmo em que tal ordenação parece ser aplicada (SAFATLE, 2008, p. 173/4).

Não obstante o autor observa, a nosso ver, corretamente, que longe de desativar o fetichismo social inerente à centralidade política do corpo (sexo) por meio de uma suposta impessoalidade extremada - indiferença da face nua em relação àquilo que o resto do seu corpo exibe: "o caráter de estranhamento de suas fotos vem do fato de ela estar absorta em dois códigos que apenas em aparência são contrários e excludentes" (SAFATLE, 2008, p. 173/4). Em total consonância com os atuais modos de reprodução 
social, analisados pelo autor no âmbito das mais recentes retóricas publicitárias, o trabalho de Chlöe des Lysses parece antes revelar uma: "solidariedade profunda entre dois pólos hiperfetichizados da economia libidinal contemporânea (a indústria da moda e a indústria da pornografia), que, conjuntamente, funcionam como duas peças de um dispositivo disciplinar fundamental da biopolítica contemporânea" (SAFATLE, 2008, p. 173/4).

Portanto, o exemplo escolhido por Aganbem parece antes conformar, e não extrapolar, a lógica inerente às pequenas narrativas publicitárias que se multiplicam na sociedade de consumo, nas quais o apelo sexual e o mercado se apresentam imbricados de um modo endêmico.

\section{Referências}

ADORNO, T. W.; HORKHEIMER, M. Dialética do esclarecimento. Rio de Janeiro: Jorge Zahar Editor, 1984.

AGANBEM, G. Profanaçõe. São Paulo: Boitempo, 2007.

DUFOUR, D. R. A Cidade Perversa: liberalismo e pornografia. Rio de Janeiro: Civilização Brasileira, 2013.

HUNT, L. (Org.). A invenção da pornografia: obscenidade e as origens da modernidade 1500 - 1800). São Paulo: Hedra, 1999.

LYOTARD, J. F. O pós-moderno. Rio de janeiro: José Olympio Editora, 1993.

KANT, I. Fundamentação da metafísica dos costumes. In: Col. Os Pensadores. São Paulo: Abril Cultural, 1980.

KENDRIK, W. The secret museum: pornography in modern culture. Ne York: Penguin, 1987.

NOVAES, A. (org.). Libertários libertinos. São Paulo: Companhia das Letras, 1996.

SADE. A filosofia na alcova. São Paulo: Iluminuras, 1999.

SAFATLE, V. Cinismo e falência da crítica. São Paulo: Boitempo, 2008.

SMITH, A. Teoria dos sentimentos morais. São Paulo: Martine Fontes, 1999.

ZARETSKY, E. Segredos da alma.: uma história sociocultural da psicanálise. São Paulo: Cultrix, 2006. 


\section{Como referenciar este artigo}

LASTÓRIA, L. A. C. N. Pornografia além da mídia. Revista Ibero-Americana de Estudos em Educação, v. 12, n. 2, p. 1117-1129, 2017. Disponível em: <http://dx.doi.org/10.21723/riaee.v12.n2.9940>. E-ISSN: 1982-5587.

Recebido em: 10/05/2017

Aprovação final em: 30/05/2017 